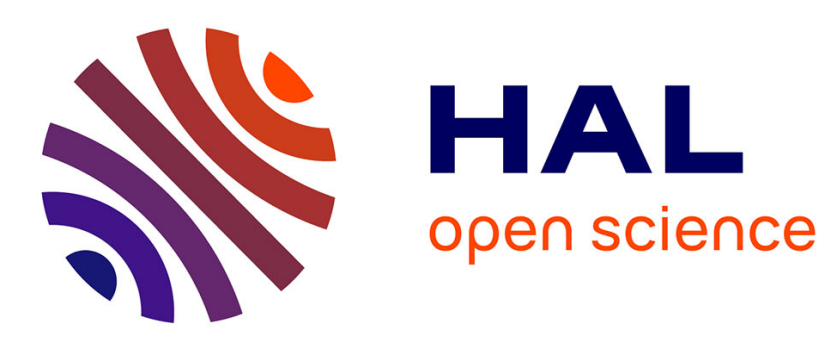

\title{
PHASE TRANSFORMATIONS ON ANNEALING OF NON-CRYSTALLINE FERROUS HALIDES
}

\author{
F. Litterst, G. Kalvius, A. Boyle
}

\section{To cite this version:}

F. Litterst, G. Kalvius, A. Boyle. PHASE TRANSFORMATIONS ON ANNEALING OF NONCRYSTALLINE FERROUS HALIDES. Journal de Physique Colloques, 1974, 35 (C6), pp.C6-403C6-406. 10.1051/jphyscol:1974678 . jpa-00215835

\section{HAL Id: jpa-00215835 https://hal.science/jpa-00215835}

Submitted on 1 Jan 1974

HAL is a multi-disciplinary open access archive for the deposit and dissemination of scientific research documents, whether they are published or not. The documents may come from teaching and research institutions in France or abroad, or from public or private research centers.
L'archive ouverte pluridisciplinaire HAL, est destinée au dépôt et à la diffusion de documents scientifiques de niveau recherche, publiés ou non, émanant des établissements d'enseignement et de recherche français ou étrangers, des laboratoires publics ou privés. 


\title{
PHASE TRANSFORMATIONS ON ANNEALING OF NON-CRYSTALLINE FERROUS HALIDES (*)
}

\author{
F. J. LITTERST, G. M. KALVIUS and A. J. F. BOYLE (**) \\ Physik-Department der Technischen Universität München \\ D 8046 Garching, James-Franck-Str., BRD
}

\begin{abstract}
Résumé. - Des échantillons non cristallins de $\mathrm{FeF}_{2}, \mathrm{FeCl}_{2}$ et $\mathrm{FeBr}_{2}$ obtenus par condensation de vapeurs à basse température, ont été convertis en phase cristalline par recuit à des températures allant jusqu'à $800 \mathrm{~K}$. On trouve que $\mathrm{FeCl}_{2}$ et $\mathrm{FeBr}_{2}$ ne se convertissent jamais directement de l'état non cristallin en l'état cristallin habituel. Ils forment entre 60 et $350 \mathrm{~K}$ une phase intermédiaire inconnue. Par contre, $\mathrm{FeF}_{2}$ se convertit directement. Ceci a lieu à des températures beaucoup plus élevées $(\sim 800 \mathrm{~K})$. L'existence d'une phase intermédiaire pour $\mathrm{FeCl}_{2}$ et $\mathrm{FeBr}_{2}$ mais non pour $\mathrm{FeF}_{2}$, est discutée en fonction des différents changements structuraux ayant lieu lors du processus de recristallisation des dihalogénures de fer non cristallins.
\end{abstract}

\begin{abstract}
Non-crystalline samples of $\mathrm{FeF}_{2}, \mathrm{FeCl}_{2}$ and $\mathrm{FeBr}_{2}$ obtained from vapour deposition at low temperatures were converted into the crystalline phase by annealing with temperatures up to $800 \mathrm{~K}$. It is found that $\mathrm{FeCl}_{2}$ and $\mathrm{FeBr}_{2}$ never convert directly from the non-crystalline to the usual crystalline state. They form an unknown intermediate phase in the temperature range between 60 and $350 \mathrm{~K}$. In contrast, $\mathrm{FeF}_{2}$ shows direct conversion. This occurs at much higher temperatures $(\sim 800 \mathrm{~K})$. The existence of an intermediate phase for $\mathrm{FeCl}_{2}$ and $\mathrm{FeBr}_{2}$, but not for $\mathrm{FeF}_{2}$, is discussed in terms of the different structural changes taking place in the recrystallization processes of the non-crystalline iron di-halides.
\end{abstract}

1. Introduction. - We have previously reported Mössbauer studies of the magnetic properties of non-crystalline samples of the anhydrous iron dihalides $\mathrm{FeF}_{2}, \mathrm{FeCl}_{2}$ and $\mathrm{FeBr}_{2}[1,2]$. In this paper we report on the observations made as these samples were converted, by annealing at increasing temperatures, into the normal crystalline state. It is shown that this conversion takes place via an intermediate phase of unknown structure.

2. Experimental results. - The samples with thicknesses of the order of $\sim 5000 \AA$ were prepared by deposition from a molecular beam onto a cold $(<10 \mathrm{~K}) \mathrm{Al}$ substrate. The vapour' pressure in the molecular beam oven was usually $10^{-5}-10^{-4}$ torr. The Mössbauer spectra observed for $\mathrm{FeCl}_{2}$ and $\mathrm{FeBr}_{2}$ at temperatures between 100 and $300 \mathrm{~K}$ are shown in figures 1 and 2 . In our previous studies we have concentrated on the behaviour of the material as it was freshly deposited at low temperatures. It was shown [1,2] that the Mössbauer spectra obtained differed considerably from those reported for the crystalline material $[3,4,5,6]$, and for one sample $\left(\mathrm{FeF}_{2}\right)$ direct evidence could be obtained by X-ray

$\left(^{*}\right)$ Work supported in part by Bundesministerium für Forschung und Technologie.

(**) Permanent address : University of Western Australia, Nedlands W. A., 6009. diffraction that the material was non-crystalline. In particular, all three iron di-halides investigated $\left(\mathrm{FeF}_{2}, \mathrm{FeCl}_{2}\right.$, and $\left.\mathrm{FeBr}_{2}\right)$ experience a magnetic transition at $\sim 20.5 \mathrm{~K}$ and show about the same saturation hyperfine (hf) field of $\sim 140 \mathrm{kOe}$ for $T \rightarrow 0 \mathrm{~K}$. Above the magnetic transition temperature a slightly broadened quadrupolar doublet is seen with a splitting about twice as large as those reported for the crystalline samples of the iron di-halides. Between $1.5 \mathrm{~K}$ and $30 \mathrm{~K}$ the samples could be thermally cycled without any noticeable irreversible effects. At higher temperatures, however, new hf pattern begin to appear which constitute the target of the present investigation.

The Mössbauer spectra for $\mathrm{FeCl}_{2}$ and $\mathrm{FeBr}_{2}$ in the temperature range between 100 and $300 \mathrm{~K}$ are shown in figures 1 and 2 . The quadrupole splitting labeled $A$ corresponds to the spectrum observed slightly above the magnetic transition temperature $(20.5 \mathrm{~K})$ of the non-crystalline material. The quadrupolar doublet seen at high temperatures $(>300 \mathrm{~K}$ ) is labeled $\mathrm{C}$. It is seen in rather pure form in figure 1, while we have not shown the pure spectrum $\mathrm{C}$ for $\mathrm{FeBr}_{2}$ in figure 2, although it can be obtained rather easily at temperatures around $350 \mathrm{~K}$. From its hf parameters spectrum C can be easily identified as belonging to the normal crystalline phases of $\mathrm{FeCl}_{2}$ and $\mathrm{FeBr}_{2}$. Not only is the value of the quadrupole splitting identical to that previously observed for crystalline samples, but also 


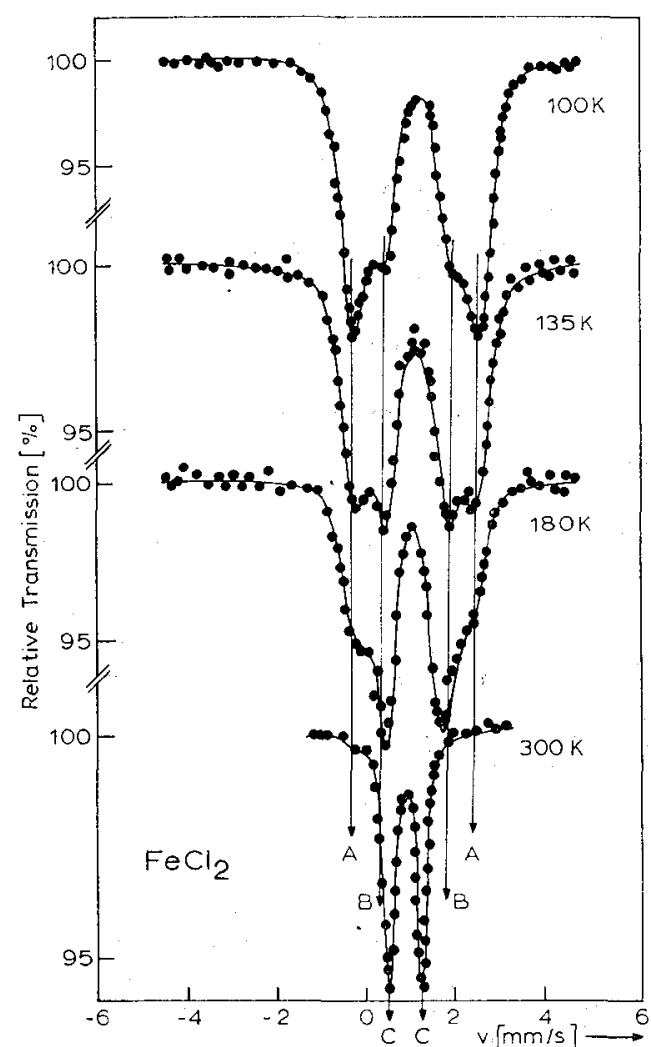

FIG. 1. - Spectra of $\mathrm{FeCl}_{2}$, deposited from a molecular beam onto $a<10 \mathrm{~K} \mathrm{Al}$ foil, for various temperatures above $100 \mathrm{~K}$.

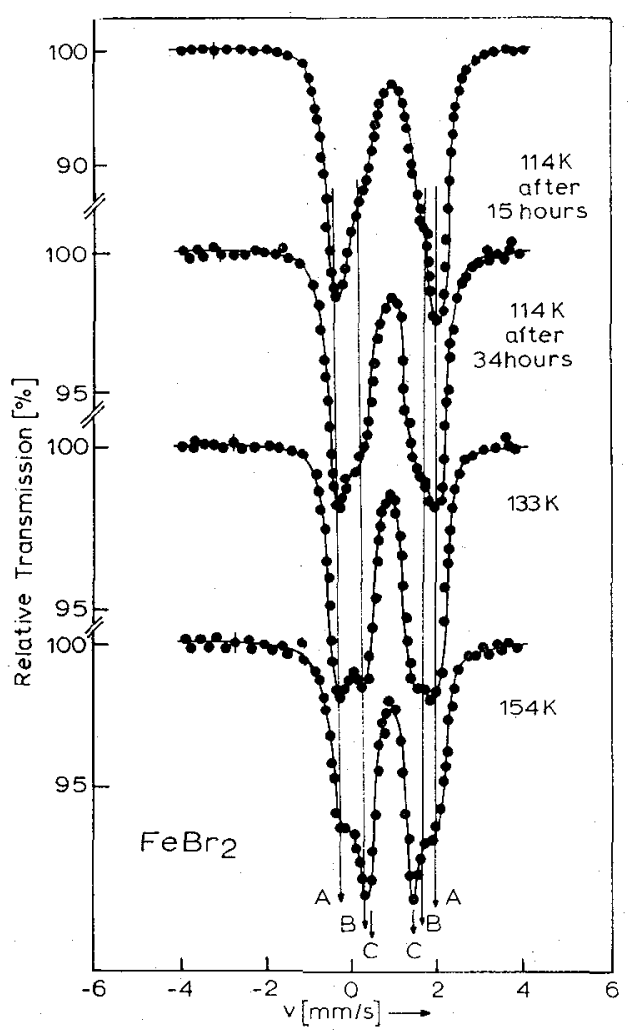

Fig. 2. - Spectra of $\mathrm{FeBr}_{2}$, deposited from a molecular beam onto $a<10 \mathrm{~K} \mathrm{Al}$ foil, for various temperatures above $100 \mathrm{~K}$. spectra obtained when the samples were again cooled to low temperatures $(4.2 \mathrm{~K})$ were those characteristic of the crystalline material.

Figure 3 shows such spectra for $\mathrm{FeBr}_{2}$. It should be kept in mind that crystalline $\mathrm{FeBr}_{2}$ has a Néel temperature of $11 \mathrm{~K}$. In the magnetic regime the hf field at

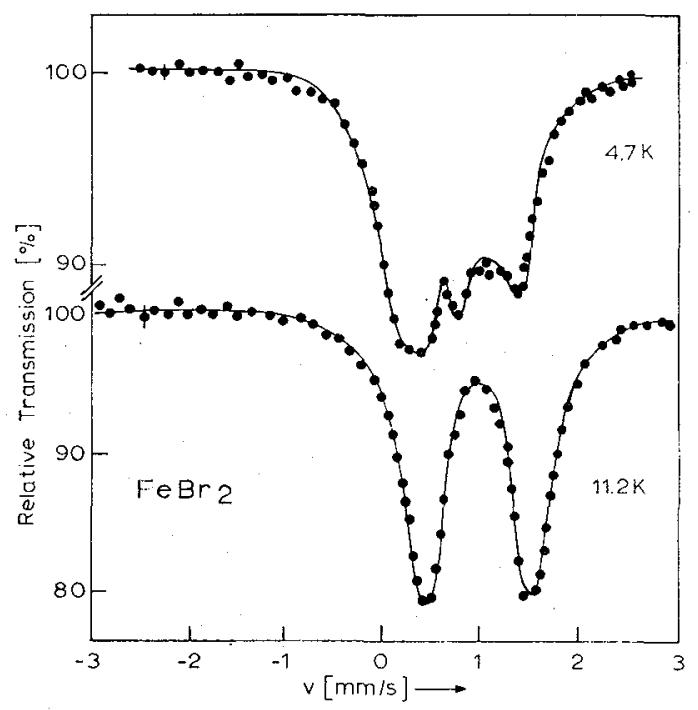

FIG. 3, - Low temperature spectra of $\mathrm{FeBr}_{2}$ converted from the non-crystalline to the crystalline state by annealing to $350 \mathrm{~K}$.

the iron is only $30 \mathrm{kOe}$ due to the contribution of the unquenched angular momentum [7]. This rather complex magnetic behaviour is fully represented in figure 3.

The most interesting feature of the spectra in figures 1 and 2 is the appearance of an intermediate phase which is characterized by the quadrupole splitting labeled B. It appears upon heating the noncrystalline samples to about $60 \mathrm{~K}$. From figures 1 and 2 it can be seen that the conversion from phase $A$ to phase $B$ and from phase $B$ to phase $C$ (normal crystalline) takes place over a wide temperature range. The crystalline phase (C) begins to form at $120 \mathrm{~K}$. All three phases can occur simultaneously. The relative intensities of the various phases in a Mössbauer spectrum depend primarily on the maximum annealing temperature and much less on the time spent at constant annealing temperature. This point is demonstrated in the top spectra of figure 2 : Keeping the sample for long times at constant temperatures results in a steady, but rather slow growth of phase $B$, while only a short time heating to more elevated temperatures leads to a much more pronounced increase in phase B. Temperature cycling shows that both phase transitions ( $A$ to $B$, and $B$ to $C$ ) are not reversible. In particular, recooling from above $100 \mathrm{~K}$ to $4.2 \mathrm{~K}$ indicates that the magnetic character of the original non-crystalline phase as described above is suppressed by the presence of phase $B$. The low temperature spectrum only shows the quadrupole splittings A and $B$ but not the broad magnetic spectrum typical for 
pure phase A. Samples of $\mathrm{FeF}_{2}$ show a slightly different behaviour. First, a much higher temperature $(\sim 800 \mathrm{~K})$ is needed for the conversion to the crystalline form (spectrum C) : secondly no evidence of an intermediate phase $B$ could be detected. The direct transition from spectrum $A$ to spectrum $C$ is again rather sluggish and irreversible.

Figures 4, 5 and 6 show the temperature variation of the quadrupole interaction in the various phases for three iron di-halides.

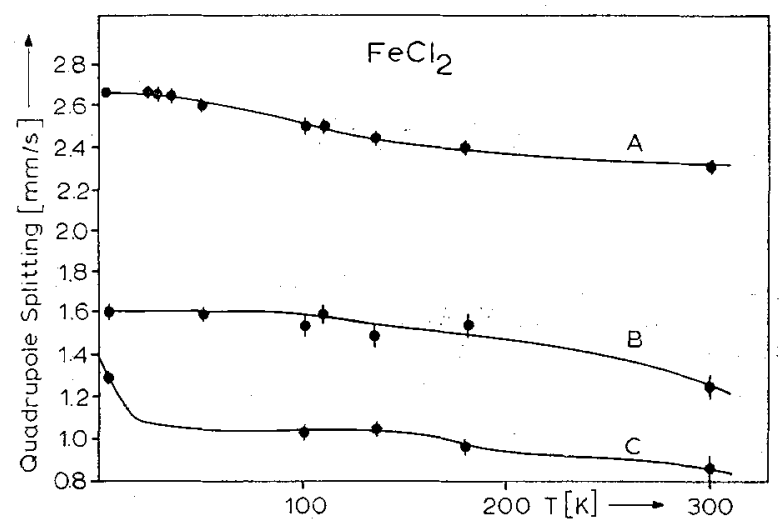

Fig. 4. - Temperature dependence of the quadrupole splitting for non-crystalline (A), intermediate (B), and crystalline (C) phases of $\mathrm{FeCl}_{2}$.

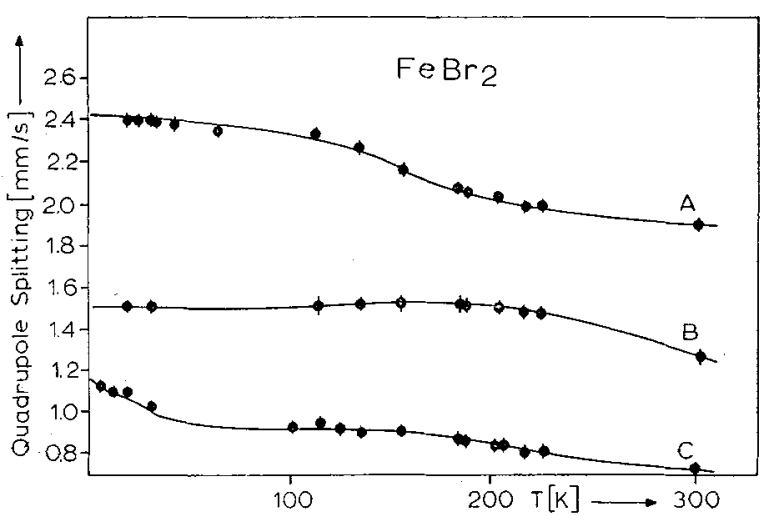

Fig. 5. - Temperature dependence of the quadrupole splitting for non-crystalline (A), intermediate (B), and crystalline (C) phases of $\mathrm{FeBr}_{2}$

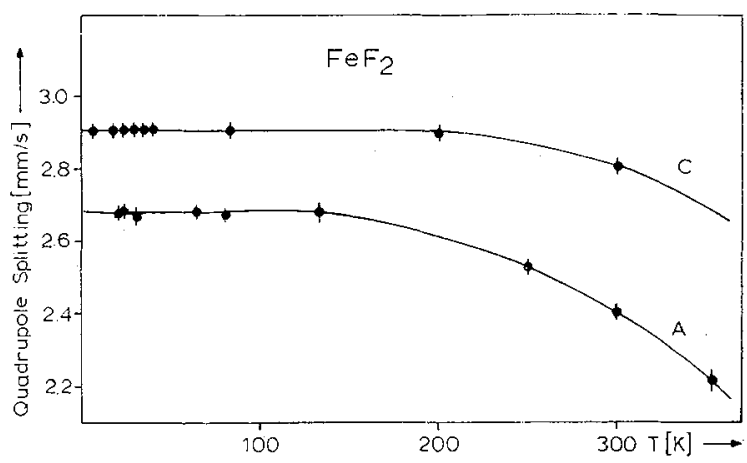

FIG. 6. - Temperature dependence of the quadrupole splitting for the non-crystalline (A) and crystalline (C) $\mathrm{FeF}_{2}$.
Samples of $\mathrm{FeCl}_{2}$ and $\mathrm{FeBr}_{2}$ were also prepared using a relatively high vapour pressure $\left(\sim 10^{-3}\right.$ torr $)$ in the molecular beam oven. In this case the spectra showed only the quadrupole doublet B; that is, the samples were produced directly in the intermediate phase with no evidence for the existence of the noncrystalline phase A which is the result of preparation a lower vapour pressure. For $\mathrm{FeF}_{2}$, changes in vapour pressure had no effect on the formation of the noncrystalline phase $\mathrm{A}$ which also was always produced in pure form.

3. Discussion. - For $\mathrm{FeF}_{2}$ the quadrupole splitting of the non-crystalline form differs only little from that of the crystalline phase [5,6] (see Fig. 6). This is consistent with the fact that the crystal is formed of linear molecules of $\mathrm{FeF}_{2}$ arranged roughly end to end in lines forming more or less discrete layers. The molecular group is dominant and this is expected also in the non-crystalline form. The transition from one form to the other therefore is thought to involve little structural change.

The quadrupole splittings of all three halides in the non-crystalline form are about equal. This suggests a similarity of the non-crystalline structure ; presumably more or less discrete molecular units are present in all three cases. The crystal structures of $\mathrm{FeCl}_{2}$ and $\mathrm{FeBr}_{2}$ are (in contrast to $\mathrm{FeF}_{2}$ ) not of this form. This is also apparent from the much smaller absolute value of the quadrupole splitting and the relative stronger variation of quadrupole splitting with temperature in the crystalline forms of $\mathrm{FeCl}_{2}$ and $\mathrm{FeBr}_{2}$; both facts suggest a much closer spacing of the two lowest crystal field levels. A greater separation of the orbital states could be expected when the axial field strength is more pronounced as it is presumably the case in the noncrystalline form.

For $\mathrm{FeCl}_{2}$ and $\mathrm{FeBr}_{2}$ there is then a substantial change in structure between the non-crystalline and the crystalline forms. The appearance of an intermediate phase can thus be understood. Unfortunately little can be said at present about the actual structure of this phase B. It is suggestive, however, that this phase is formed directly from the high pressure vapour in which case it is known from mass spectroscopy that $\mathrm{FeCl}_{2}$ and $\mathrm{FeBr}_{2}$ are present to a considerable amount $(\sim 10-20 \%)$ in the form of dimers [8,9]. In this form the strongly axial structure of the single molecule is less pronounced and the quadrupole splitting would be expected to be smaller. This is indeed the case in the intermediate phase.

One curious feature of the present results is the suppression of the appearance of the magnetic transition in the non-crystalline phase by the presence of only a small amount of the intermediate phase. It is unlikely that the transition itself no longer occurs and it must be suggested that the observation of the magnetic hf spectrum is prevented by some type of relaxation of the spins. It is possible that the intermediate phase is 
formed preferentially along lines which effectively divide the layer into small unconnected regions of the non-crystalline phase. Each of these regions could be of a size that would exhibit superparamagnetic effects $[10,11]$ that is a relaxation of the macroscopic spin of the whole region. It is well known that in such circumstances the effective magnetic field at the nucleus may average to zero within the characteristic time span for Mössbauer spectroscopy.

Acknowledgement. - We gratefully acknowledge J. M. Friedt for the preparation of anhydrous $\mathrm{FeF}_{2}$. One of us (A. J. F. B.) would like to thank the PhysikDepartment for its hospitality.

\section{References}

[1] Boyle, A. J. F., Kalvius, G. M., Gruen, D. M., Clifton, J. R., MCBeth, R. L., J. Physique Colloq. 32 (1971) C 1-224.

[2] Litterst, F. J., Kalvius, G. M., Boyle, A. J. F., Proc. 19th Conf. Magnetism and Magnetic Materials (1973) Boston, AIP Conf. Series. 18, 616, Graham C. D. Jr., Rhyne J. J., eds.

[3] Ono, K., Iтo, A., Fujita, T., J. Phys. Soc. Japan 19 (1964) 2119.

[4] Fujita, T., Ito, A., Ono, K., J. Phys. Soc. Japan 27 (1969) 1143.
[5] Ganirl, U., Shtrikman, S., Phys. Rev. 177 (1969) 503.

[6] Perkins, H. K., Hazony, Y., Phys. Rev. B 5 (1972) 7.

[7] Simkin, D. J., Phys. Rev. 177 (1969) 1008.

[8] Schoonmaker, R. C., Porter, R. F., J. Chem. Phys. 29 (1958) 116, and J. Phys. Chem. 63 (1959) 626.

[9] Gregory, N. W., Maclaren, R. O., J. Phys. Chem. 59 (1955) 110 and 184.

[10] J ACOBS, I. S., BeAN, C. P., in Magnetism III (Acad. Press, London, New York) eds. Rado, Suhl (1963) 271.

[11] K ündig, W., Bömmel, H., Constabaris, C., Lindquist, R. H., Phys. Rev. 142 (1966) 327. 